\title{
Design and Experimentation of New Balancing Technique Based on the Jeffcott Rotor Model
}

\author{
Prof. Avadhut R. Koli, Assistant Professor, TKIET, Warananagar, India, arkoli@ tkietwarana.ac.in
}

Prof. Amar. M. Patil, Assistant Professor, TKIET, Warananagar, India, ampmech@ tkietwarana.ac.in

Prof. Shailesh S. Patil, Assistant Professor, TKIET, Warananagar, India, shaileshspatil@tkietwarana.ac.in

Prof. Vivek V. Patil,Assistant Professor, TKIET, Warananagar, India, vvpatil@tkietwarana.ac.in

Abstract: Unbalance is one of the most common causes of machinery vibrations, present in rotating machines. The influence coefficient method of balancing used for in-situ balancing requires vibration data (Phase angles and vibration values) of many trial runs which may result in a lengthy balancing process. The vibration data can be measured with the help state-of-the-art four channel Adash 4400 VA4 Pro FFT analyzer platform along with data acquisition system and electronic instrumentation. It has been identified in the literature that it is possible to balance the rotor without the use of trial weight. This paper presents a new systematic approach of balancing method based on the Jeffcott rotor dynamic model. The mathematical model on Jeffcott rotor model is presented here. The proposed method requires vibration data of two test runs at different speeds without trial weight. For experimental verification of proposed method, a test rig has been developed. Systematic experiments done on the Jeffcott rotor model at different rotating speed are described in this paper. The experimental results shows the success of proposed balancing method. The importance of identifying type of rotor unbalance (static, couple, quasi-static, or dynamic) and the method to detect type of unbalance present in the rotor is presented.

Keywords: Unbalance, Static, Couple, Quasi-static, Dynamic, Influence coefficient method, In-situ balancing, Phase angle, FFT Analyzer, MATLAB code, Jeffcott Rotor Model.

\section{INTRODUCTION}

The vibration of rotating shafts is a source of inefficiency in the operation of a wide range of machinery in many industries. Unbalance is one of the most common causes of machinery vibration, present in rotating machines. Balancing is the process to find amount and location of unbalance spot present in the rotor. Balancing is the process of aligning a principal inertia axis with the geometric axis of rotation through the addition or removal of material. By doing so, the centrifugal forces are reduced, minimizing vibration, noise and associated wear. Virtually all rotating components experience significant improvements when balanced.

\section{LITERATURE SURVEY}

There are many procedures available to balance rotating systems. Many investigators have studied and developed new methods for balancing of rotors. Now-a-days the influence coefficient method and modal balancing method are the two major balancing methods that are used extensively. The influence coefficient method requires vibration data (Phase angles and vibration values) measured at different locations on a bearing, at a single speed. Chigbogu et al. [1] derived number of analytical equations to overcome the challenges of graphical approach to single and double plane balancing. The general MATLAB program has been written for quick solution of experimental double plane balancing problems. The presented MATLAB program for double plane balancing would facilitate conversion of measured unbalance into balancing solutions thus increasing productivity.Liang et al. [2] presented equivalent phase difference mapping relationship between incentive and vibration response for single- disk rotor system. Characteristics of influence coefficient method have been analyzed. Measurement of phase angle has been analyzed by using key pulse method and Discrete Fourier Transform. Differential equations and Laplace transform theory used to solve the equations. Xiaoping [3] developed the general influence coefficient algorithm for calculation of influence coefficients. This algorithm requires assumption of linearity of the rotor system and the measuring system for easy field balancing. It is an empirical method, which characterizes a rotor system in terms of its response to single trial weights. Feese and Grazier [4] made a research on six case histories, which illustrate actual difficulties that are encountered while trying to field balance various types of rotating machinery. All the case studies gives the brief overview of the common types of unbalance, theories and criteria used when balancing 
rotating machines. This paper also cover the brief description of vector method, four run method, modal balancing and Influence coefficient balancing.Eduardo and Bannister [5] carried research on balancing of rotor without trial runs. The attempts have been made to combine the influence coefficient method and modal balancing method.Zhou and Shi [6] presented an adaptive active balancing strategy for a rotor system. Optimal one-plane balancing strategy which minimizes vibrations due to unbalance is described in detail. They developed an analytical equation to describe the unbalance response of a Jeffcott rotor during acceleration.Shiyu and Jianjun [7] carried research on real-time active balancing and active vibration control for rotating machinery. They presented dynamic modeling and analysis technique of rotor systems. This research concluded that active balancing can suppress the unbalance induced vibrations and improve fatigue life of the machine. Foiles et al. [8] made a review on various balancing techniques. Review includes influence coefficient, unified, modal, no phase, and no amplitude methods of balancing. Parkinson [9] carried out a research on the balancing procedures for rigid and flexible shaft, but emphasis has been given to a review of techniques for the high speed balancing of flexible shafts. The brief description given on modal balancing of flexible shafts, rigid rotor balancing and influence coefficient balancing.Ramamurti and Anantaraman [10] made a research on phase angle method and the seven-run method used in the field to balance rigid rotors. The solutions of these two methods are mathematically exact but practically this is not always true. The reasons for deviation mathematical solution and practical solution have been discussed.Everett [11-12] presented a two-plane balancing technique which is simple to use, and does not require measurement of vibration phase angles. This method does not require more runs than standard technique. The method extends the four-run single plane method and has greatest utility when the two- plane influence coefficient method fails to obtain the desired state of balance quality due to inaccuracies in phase measurement. Cunningham [13] presented a brief comparison of shop vs. in-field methods of dynamic balancing. Also need of balancing, different types of unbalance and balancing tolerance standards have been explained. This work given an idea about how to choose balancing method, in-shop or in-field balancing.Fox [14] provided information which is necessary to solve the majority of balancing problems both in the field and in the balancing shop. The brief description has been given about basic principles of balancing, single plane vector method of balancing, four- step method for single plane balancing, balancing in one run, types of unbalance, single-plane vector method for two plane balancing and balancing overhung rotors. Patil et. al [15] presented the measurement and vibration analysis using accelerometer and dynamic signal analyser.

\section{MATHEMATICAL MODELLING OF ROTOR}

The simplest model of isotropic rotor supported by two isotropic bearings and excited by unbalance was proposed by Jeffcott. H.H. Jeffcott, in 1919, explained the fundamental response of a single mass flexible rotor to unbalance. Fig. 1 shows the representation of rigid rotor useful for mathematical analysis. The rotor of mass $M$, is supported in two identical isotropic bearings of stiffness $\mathrm{k}$ and damping $\mathrm{c}$. The unbalance is represented as a lumped mass $\mathrm{m}_{\mathrm{u}}$ located at a radial distance $\mathrm{d}$ from the axis of rotation which is along $\mathrm{y}$ axis and at an angle $\alpha$ from positive $\mathrm{x}$ axis in $\mathrm{xz}$ plane. Let $\omega$ be the speed of rotation of the rotor.

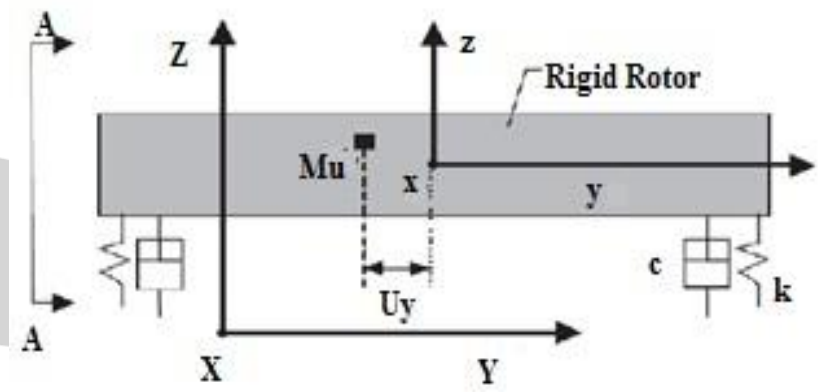

Figure 1 Rigid rotor model [6]

If initial transient vibrations and rotor free response is neglected, the rotor excited by unbalance force modeled as$\mathrm{M} \ddot{z}+\mathrm{cz}+\mathrm{kz}=\mathrm{m}_{\mathrm{u}} \mathrm{d} \omega^{2} \mathrm{e}^{\mathrm{j}(\omega \mathrm{t}+\alpha)}[6]$ $M \ddot{x}+c \dot{x}+k x=m_{u} d \omega^{2} e^{j(\omega t+\alpha)} \quad[6]$

It is important to note that due to bearing isotropy, motion of the rotor in $\mathrm{x}$ and $\mathrm{z}$ direction is the same. The rotor response is given by-

$\mathrm{z}=B \mathrm{e}^{\mathrm{j}(\omega \mathrm{t}+\beta)}$

The response amplitude and phase calculated as-

$B=\frac{m_{u} e \omega^{2}}{\sqrt{\left(k-m \omega^{2}\right)^{2}+(c \omega)^{2}}}$
$\beta=\alpha-\arctan \left(\frac{c \omega}{k-m \omega^{2}}\right)$

The quantity in the denominator of the equation (4) is called as Complex Dynamic Stiffness of the system. This is the simplest rotor model which is used for predicting rotor response to the unbalance. This model is based on a few simplifying assumptions like isotropic nature of rotor, neglecting rotor material damping, neglecting rotor static bending.

\section{THE BALANCING FORMULATION}

The angular phase of the vibration response is identified as high point on the rotor. Radial distance of the high point from the axis of the rotor is proportional to vibration magnitude. Fig. 2 indicates the high point and heavy point on the rotor. It is clear that there is always a phase difference between heavy point, which is the cause of 
vibration, and the high point, which is the vibration response. This is primarily due to damping present in the rotor system. The task of balancing of rotor becomes difficult because, during the balancing process, the target is to locate the heavy point but direct measurement gives high point. Therefore in this paper, new method to identify the unbalance parameters which include both magnitude and phase angle is developed. All the phase angles are defined counter clockwise from reference mark. The proposed balancing method is based on the equations of motion of Jeffcott rotor.

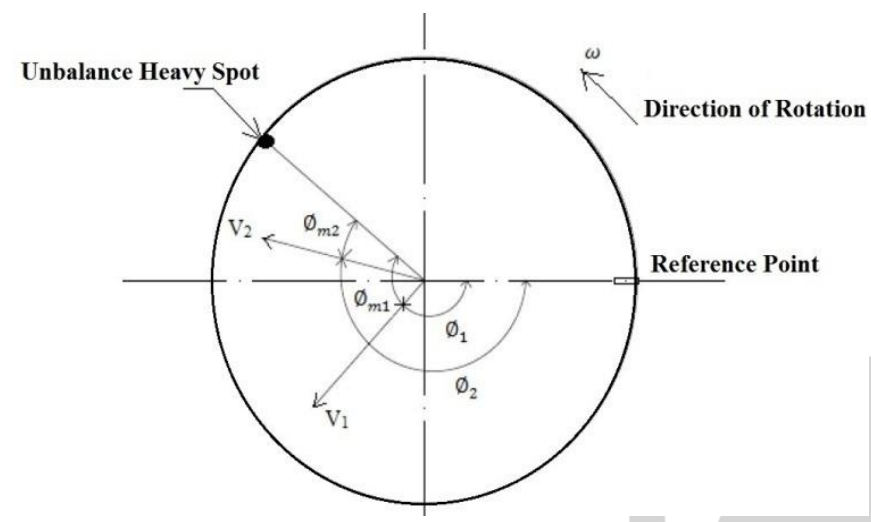

Figure 2 Rotor with unbalance heavy spot

From the Jeffcott rotor, vibration response amplitude-

$$
\mathrm{Z}_{\mathrm{m}}=\frac{\mathrm{Me} \omega^{2}}{\mathrm{~V}}=\sqrt{\mathrm{R}_{\mathrm{m}}^{2}+\left(\omega \mathrm{M}-\frac{\mathrm{k}}{\omega}\right)^{2}}
$$

Phase of force with respect to velocity-

$$
\emptyset_{\mathrm{m}}=\tan ^{-1}\left(\frac{\omega \mathrm{M}-\frac{\mathrm{k}}{\omega}}{\mathrm{R}_{\mathrm{m}}}\right)
$$

Since the number of unknown parameters is four, two sampling speeds are required. Therefore above two equations have been used for two different speeds and one more equation has been derived from figure 2 as follow-

$\emptyset_{1}+\emptyset_{\mathrm{m} 1}=\emptyset_{2}+\emptyset_{\mathrm{m} 2}$

The solution of equation (6), (7) and (8) is as follow-

$$
\begin{aligned}
& \emptyset_{\mathrm{m} 1}=\tan ^{-1}\left[\cot \left(\emptyset_{1}-\emptyset_{2}\right)-\left(\frac{\mathrm{V}_{2}}{\mathrm{~V}_{1}}\right)\left(\frac{\omega_{1}}{\omega_{2}}\right)^{2} \csc \left(\emptyset_{1}-\emptyset_{2}\right)\right] \\
& \emptyset_{\mathrm{m} 2}=\left(\emptyset_{1}-\emptyset_{2}\right)+\tan ^{-1}\left[\cot \left(\emptyset_{1}-\emptyset_{2}\right)\right. \\
& \left.-\left(\frac{\mathrm{V}_{2}}{\mathrm{~V}_{1}}\right)\left(\frac{\omega_{1}}{\omega_{2}}\right)^{2} \csc \left(\emptyset_{1}-\emptyset_{2}\right)\right] \\
& \mathrm{k}=\frac{\mathrm{M}\left[\omega_{1}^{2}-\omega_{2}^{2}\left(\frac{\omega_{1}}{\omega_{2}}\right)\left(\frac{\tan \emptyset_{\mathrm{m} 1}}{\tan \emptyset_{\mathrm{m} 2}}\right)\right]}{\left[1-\left(\frac{\omega_{1}}{\omega_{2}}\right)\left(\frac{\tan \emptyset_{\mathrm{m} 1}}{\tan \emptyset_{\mathrm{m} 2}}\right)\right]} \\
& \mathrm{R}_{\mathrm{m}}=\left(\frac{\omega_{1} \mathrm{M}-\frac{\mathrm{k}}{\omega_{1}}}{\tan \emptyset_{\mathrm{m} 1}}\right) \quad \text { or } \quad \mathrm{R}_{\mathrm{m}}=\left(\frac{\omega_{2} \mathrm{M}-\frac{\mathrm{k}}{\omega_{2}}}{\tan \emptyset_{\mathrm{m} 2}}\right) \\
& \mathrm{e}=\frac{\mathrm{R}_{\mathrm{m}} \mathrm{V}_{1} \sec \emptyset_{\mathrm{m} 1}}{\mathrm{M} \omega_{1}^{2}} \quad \text { or } \quad \mathrm{e}=\frac{\mathrm{R}_{\mathrm{m}} \mathrm{V}_{2} \sec \emptyset_{\mathrm{m} 2}}{\mathrm{M} \omega_{2}^{2}}
\end{aligned}
$$

$\emptyset_{\mathrm{m} 1}$ and $\emptyset_{\mathrm{m} 2}$ Provide the location of unbalance force vector from velocity vector.
Now to find the magnitude of unbalance, equation (14) has been derived. In this equation mass of rotor ' $M$ ', and distance ' $r$ ' from the center of rotor are known. After calculating the distance of unbalance mass ' $\mathrm{e}$ ' from the center of rotor by using equation (13), it is possible to find out the amount of balancing mass required.

$\mathrm{M} \times \mathrm{e}=\mathrm{m} \times \mathrm{r}$

Thus, with the help of above equations, it is possible to get the unbalance parameters. For experimental verification of new method, a test rig has been designed and developed. The model of experimental set-up is explained in the next section.

\section{EXPERIMENTATION}

\section{A. Experimental set-up}

The test rig for analysis of dynamic unbalance of rotors is as shown in fig. 3. It has $3 \mathrm{HP}$ motor with speed of 1440 $\mathrm{rpm}$. It has been made to operate the motor with the help of VFD (Variable Frequency Drive) at above $1440 \mathrm{rpm}$. The test rig consists of four rotors mounted on shaft with equal distance apart. The twelve holes are provided on all rotors so that unbalance can be created and balance weight can be added at any location. The shaft is provided with throughout keyway so that rotors can be fixed at various locations in axial direction. The shaft is supported between two self-aligning ball bearings. The rotor shaft and motor shaft are connected by jaw type rigid coupling.

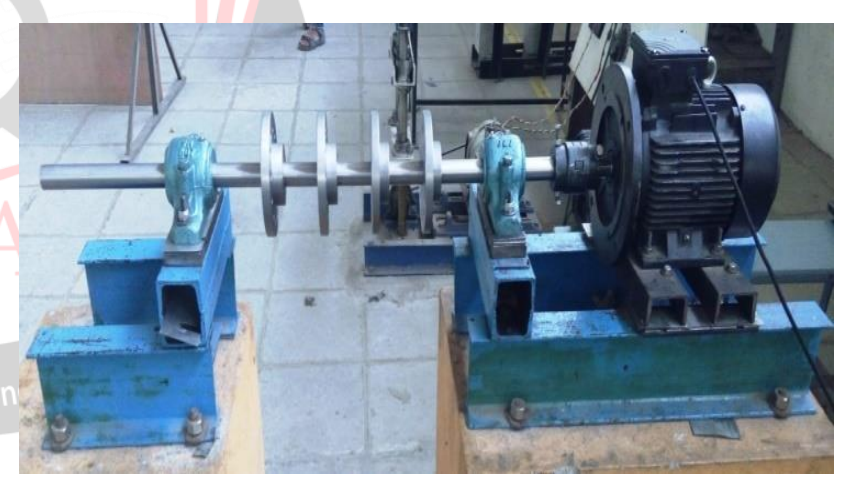

Figure 3 Experimental Test Rig

\section{B. Vibration Data Measurement}

The new method to identify the unbalance parameters which include both magnitude and phase angle has been explained in above section. To prove the validation of the proposed method, different experiments have been performed on the test rig. The trial weights attached on different planes alternatively and vibration data is measured with the help of four channel Adash 4400 VA4 Pro FFT analyzer platform as shown in figure 4, along with accelerometer and accelerometer cable as shown in figure 5 and figure 6 . 


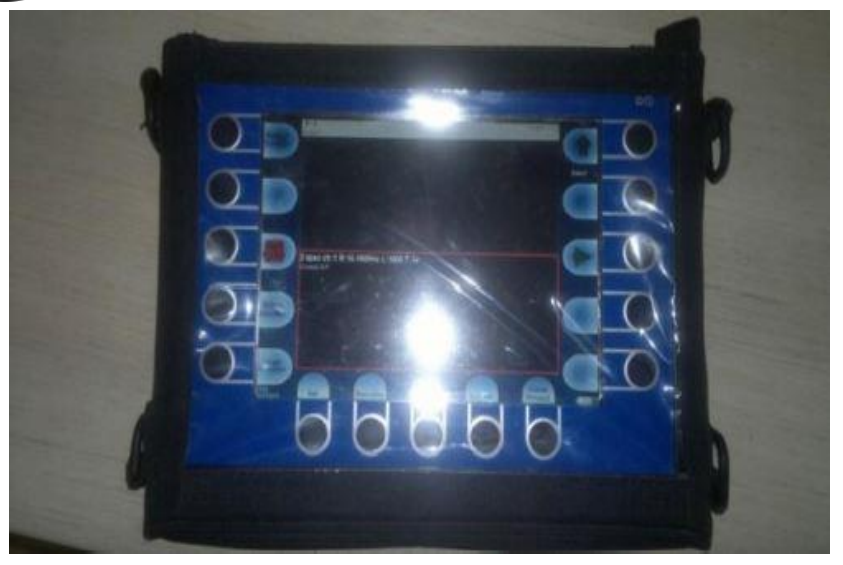

Figure 4 FFT Analyzer

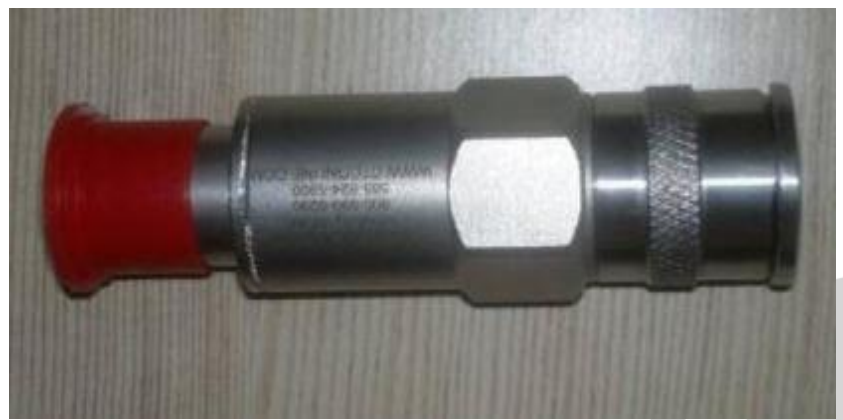

Figure 5 Accelerometer

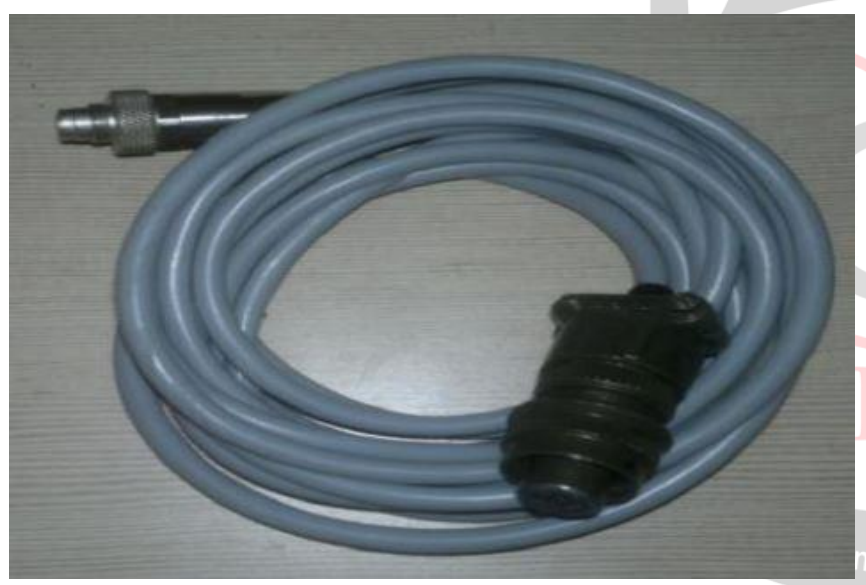

Figure 6 Accelerometer Cable

Experiment:-102 gram weight is attached at $90^{\circ}$ on plane 1 from drive end.

In this experiment known amount of unbalance created by attaching trial weight at known location on plane 1. The measured vibration parameters on both the bearings at different speeds are listed in Table 1. The measured vibration readings has been used in new balancing method to validate the known results.

Table 1 Vibration parameters on both drive (DE) end and non-drive end (NDE) bearings at different speeds due to unbalance mass on plane 1

\begin{tabular}{|c|c|c|c|c|}
\hline \multirow{2}{*}{ Speed(RPM) } & \multicolumn{2}{|c|}{ DE Bearing } & \multicolumn{2}{c|}{ NDE Bearing } \\
\cline { 2 - 5 } & $\begin{array}{c}\text { Velocity } \\
(\mathrm{mm} / \mathrm{s})\end{array}$ & $\begin{array}{c}\text { Phase } \\
\text { Angle } \\
\text { (Degree) }\end{array}$ & $\begin{array}{c}\text { Velocity } \\
(\mathrm{mm} / \mathrm{s})\end{array}$ & $\begin{array}{c}\text { Phase } \\
\text { Angle } \\
\text { (Degree) }\end{array}$ \\
\hline 800 & 0.551 & 14 & 0.325 & 28 \\
\hline 900 & 0.74 & 18 & 0.459 & 29 \\
\hline
\end{tabular}

\begin{tabular}{|c|c|c|c|c|}
\hline 1000 & 1.03 & 23 & 0.634 & 34 \\
\hline 1100 & 1.378 & 27 & 0.871 & 38 \\
\hline 1200 & 1.83 & 28 & 1.15 & 40 \\
\hline 1300 & 2.47 & 33 & 1.55 & 45 \\
\hline 1400 & 3.28 & 35 & 2.02 & 46 \\
\hline 1500 & 4.42 & 43 & 2.7 & 54 \\
\hline 1600 & 6.06 & 45 & 3.56 & 56 \\
\hline 1700 & 8.72 & 48 & 4.76 & 58 \\
\hline
\end{tabular}

\section{Calculation of amount and location of unbalance}

The validation of new method of balancing has been done by taking vibration parameters at any two different speeds. The phase difference between two readings must be greater than $30^{\circ}$ for satisfactory results. In the above experiment unbalance has been created at particular known location from the reference point. It is required to find the created unbalance and location using derived equations. For better understanding of mathematical treatment required for balancing of the rotor, MATLAB code has been developed which can be used for balancing. For validation of new balancing method, the vibration parameters at two different speeds (900 RPM and 1700 RPM) have been used in MATLAB code as given in Table 2.

Table 2 Vibration parameters at two different speeds for validation of

\begin{tabular}{|c|c|c|}
\hline \multirow{2}{*}{ Speed (RPM) } & \multicolumn{2}{|c|}{ new balancing method. } \\
\cline { 2 - 3 } & Velocity $(\mathrm{mm} / \mathrm{s})$ & Phase Angle (Degree) \\
\hline 900 & 0.74 & 18 \\
\hline 1700 & 8.72 & 48 \\
\hline
\end{tabular}

The results of MATLAB code are as follow,

$$
\begin{array}{lc}
\emptyset_{\mathrm{m} 1}=78.40410 & \emptyset_{\mathrm{m} 2}=47.40410 \\
\mathrm{~K}=1.2342 \mathrm{e}+006, & \mathrm{R}_{\mathrm{m}}=2.2037 \mathrm{e}+003 \\
\mathrm{e}=0.0365 & \mathrm{~m}=16.59
\end{array}
$$

Therefore location of unbalance mass from reference point is,

$$
\emptyset_{1}+\emptyset_{\mathrm{m} 1}=18+78.4041=96.4041^{\circ} \text { Or }
$$$$
\emptyset_{2}+\emptyset_{\mathrm{m} 2}=48+49.4041=96.4041^{\circ}
$$

The amount of unbalance mass $=16.59$ gram

The results of the derived equations shows that, unbalance of 16.59 gram present at $96.4041^{\circ}$. The new method gives approximate location and mass of unbalance. To get the accurate results similar experiments were performed on different planes.

\section{VIBRATION DATA MEASUREMENT FOR DETECTION OF TYPE OF UNBALANCE IN ROTOR}

The location of the mass center and the principal inertia axes are determined by the distribution of mass within the part. Unbalance exists when the axis of rotation is not coincident with a principal inertia axis. The International Standards Organization (ISO) defines four basic types of unbalance in their standards 1925 that covers balancing 
technology [7]. These are static unbalance, couple unbalance, quasi-static unbalance, and dynamic unbalance. Each type of unbalance is defined by the relationship between the central principal axis and the rotating centerline of the machine. The central principal axis is the axis about which the weight of a rotor is equally distributed.

\section{Static Unbalance}

A condition of static unbalance exists when the mass center does not lie on the axis of rotation. Static unbalance is also known as force unbalance. Static unbalance is an ideal condition; it has the additional condition that the axis of rotation be parallel to the central principal axis. The static unbalance has been created by attaching five trial masses on five rotors at same location on same straight line as shown in figure 7.

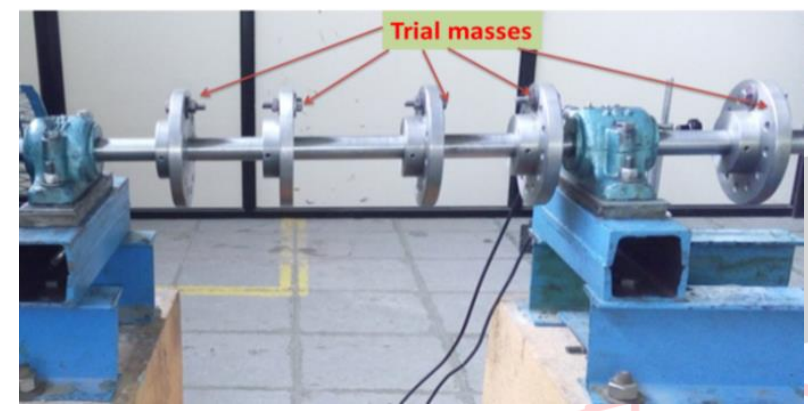

Figure 7 Static unbalance

The vibration parameters measured on both the bearings at different speeds are given in Table 3.

Table 3 Effect of static unbalance on vibration parameters at various rotor speeds.

\begin{tabular}{|c|c|c|c|c|}
\hline \multirow{2}{*}{$\begin{array}{c}\text { Speed } \\
(\mathrm{RPM})\end{array}$} & \multicolumn{2}{|c|}{ DE Bearing } & \multicolumn{2}{c|}{ NDE Bearing } \\
\cline { 2 - 5 } & $\begin{array}{c}\text { Velocity } \\
(\mathrm{mm} / \mathrm{s})\end{array}$ & $\begin{array}{c}\text { Phase } \\
\text { Angle } \\
(\text { Degree })\end{array}$ & $\begin{array}{c}\text { Velocity } \\
(\mathrm{mm} / \mathrm{s})\end{array}$ & $\begin{array}{c}\text { Phase } \\
\text { Angle } \\
\text { (Degree) }\end{array}$ \\
\hline 600 & 0.357 & 12 & 0.829 & $21 / \mathrm{ch}$ \\
\hline 800 & 1.81 & 31 & 0.675 & 21 \\
\hline 1000 & 1.26 & 30 & 2.61 & 38 \\
\hline 1200 & 2.16 & 36 & 3.86 & 43 \\
\hline 1400 & 3.92 & 44 & 4.9 & 50 \\
\hline 1600 & 8.01 & 56 & 10.2 & 59 \\
\hline
\end{tabular}

\section{Couple Unbalance}

A couple is simply two parallel equal forces acting in opposite directions but not on the same straight line. Couple unbalance is that condition of unbalance where the central principal axis intersects the rotating centerline at the rotor center of gravity. Couple unbalance condition has been created by attaching trial masses at each end of the rotor but on the opposite sides of the centerline as shown in figure 8 .

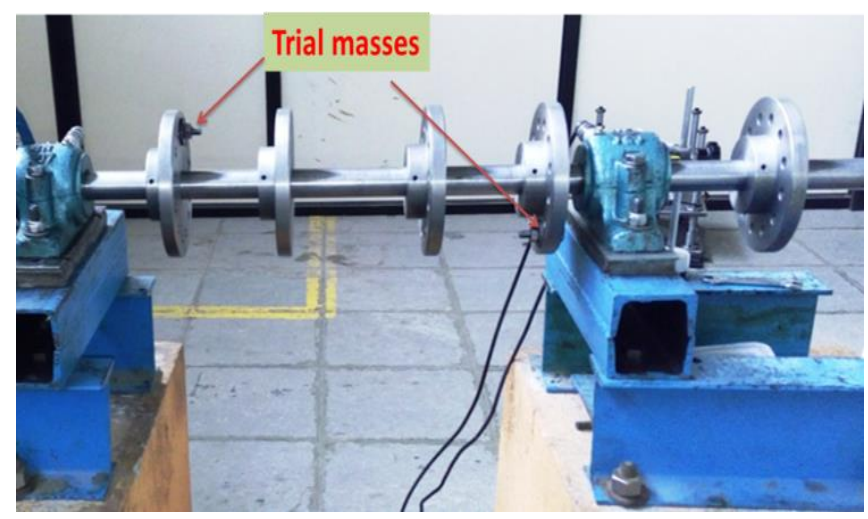

Figure 8 Couple unbalance

The vibration parameters measured on both the bearings at different speeds are given in Table 4.

Table 4 Effect of couple unbalance on vibration parameters at various rotor speeds

\begin{tabular}{|c|c|c|c|c|}
\hline \multirow{2}{*}{$\begin{array}{c}\text { Speed } \\
(\mathrm{RPM})\end{array}$} & $\begin{array}{c}\text { Velocity } \\
(\mathrm{mm} / \mathrm{s})\end{array}$ & $\begin{array}{c}\text { Phase } \\
\text { Angle } \\
(\text { Degree })\end{array}$ & $\begin{array}{c}\text { Velocity } \\
(\mathrm{mm} / \mathrm{s})\end{array}$ & $\begin{array}{c}\text { Phase } \\
\text { Angle } \\
(\text { Degree })\end{array}$ \\
\cline { 2 - 5 } & 0.177 & 10 & 0.117 & 186 \\
\hline 600 & 0.329 & 21 & 0.272 & 199 \\
\hline 800 & 0.496 & 31 & 0.564 & 207 \\
\hline 1000 & 0.945 & 34 & 0.892 & 212 \\
\hline 1200 & 1.49 & 40 & 1.63 & 218 \\
\hline 1400 & 2.49 & 50 & 2.73 & 226 \\
\hline 1600 & & &
\end{tabular}

\section{Quasi-static Unbalance}

The quasi-static unbalance is combination of static and couple unbalance, where the static unbalance is directly in line with one of the couple moments. Quasi-static Unbalance is that condition where the central principal axis intersect the rotating centerline but not at the rotor center of gravity. The quasi-static unbalance has been created by attaching trial masses at each end of the rotor but on opposite side of centerline same as couple unbalance. One more trial mass has been attached on another rotor in line with one of end rotor as shown in figure 9.

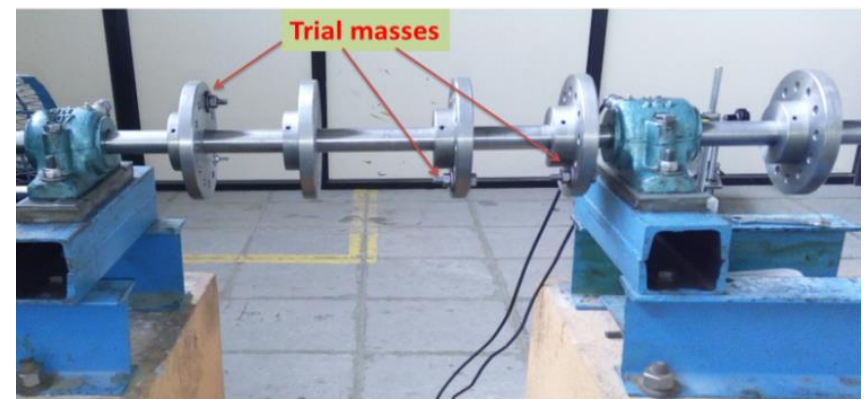

Figure 9 Quasi-static unbalance

The vibration parameters measured on both the bearings at different speeds are given in Table 5. 
Table 5 Effect of Quasi-static unbalance on vibration parameters at various rotor speeds.

\begin{tabular}{|c|c|c|c|c|}
\hline \multirow{2}{*}{$\begin{array}{c}\text { Speed } \\
(\mathrm{RPM})\end{array}$} & $\begin{array}{c}\text { Velocity } \\
(\mathrm{mm} / \mathrm{s})\end{array}$ & $\begin{array}{c}\text { Phase } \\
\text { Angle } \\
\text { (Degree })\end{array}$ & $\begin{array}{c}\text { Velocity } \\
(\mathrm{mm} / \mathrm{s})\end{array}$ & $\begin{array}{c}\text { Phase } \\
\text { Angle } \\
\text { (Degree })\end{array}$ \\
\hline \multirow{2yyyy}{*}{600} & 0.131 & 11 & 0.164 & 197 \\
\hline 800 & 0.213 & 17 & 0.471 & 203 \\
\hline 1000 & 0.311 & 27 & 1.08 & 210 \\
\hline 1200 & 0.446 & 30 & 2.45 & 219 \\
\hline 1400 & 0.739 & 35 & 4.33 & 225 \\
\hline 1600 & 1.02 & 38 & 6.86 & 230 \\
\hline
\end{tabular}

\section{Dynamic Unbalance}

Dynamic unbalance is the most common type of unbalance. The dynamic unbalance exist whenever static and couple unbalance are present but where the static unbalance is not in direct line with either couple component. In dynamic unbalance central principal axis and rotating centerline do not coincide or touch. The dynamic unbalance has been created by attaching trial weights as shown in figure 10 .

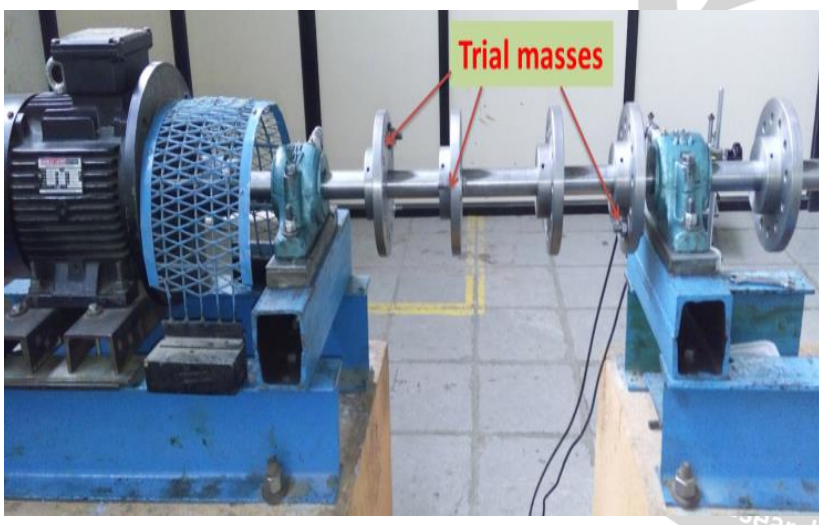

Figure 10 Dynamic unbalance

The vibration parameters measured on both the bearings at different speeds are given in Table 6.

Table 6 Effect of dynamic unbalance on vibration parameters at various rotor speeds

\begin{tabular}{|c|c|c|c|c|}
\hline \multirow{2}{*}{ Speed (RPM) } & \multicolumn{2}{|c|}{ DE Bearing } & \multicolumn{2}{c|}{ NDE Bearing } \\
\cline { 2 - 5 } & $\begin{array}{c}\text { Velocity } \\
(\mathrm{mm} / \mathrm{s})\end{array}$ & $\begin{array}{c}\text { Phase } \\
\text { Angle } \\
\text { (Degree) }\end{array}$ & $\begin{array}{c}\text { Velocity } \\
(\mathrm{mm} / \mathrm{s})\end{array}$ & $\begin{array}{c}\text { Phase } \\
\text { Angle } \\
\text { (Degree) }\end{array}$ \\
\hline 600 & 0.167 & 24 & 0.191 & 142 \\
\hline 800 & 0.424 & 33 & 0.471 & 153 \\
\hline 1000 & 0.696 & 48 & 0.836 & 150 \\
\hline 1200 & 1.14 & 54 & 1.61 & 159 \\
\hline 1400 & 1.89 & 63 & 3.46 & 176 \\
\hline 1600 & 2.81 & 80 & 5.91 & 184 \\
\hline
\end{tabular}

\section{RESULTS AND DISCUSSION}

The test data on both drive end and non-drive end bearings for different types of unbalances is analyzed and figures are plotted as shown below. Figure 11 to Figure 18 gives comparison of the effect of different types of unbalances on bearings and from which it is possible to identify the type of unbalance present in rotor.

Effect of Static Unbalance on Vibration Parameters at Various Rotor Speeds

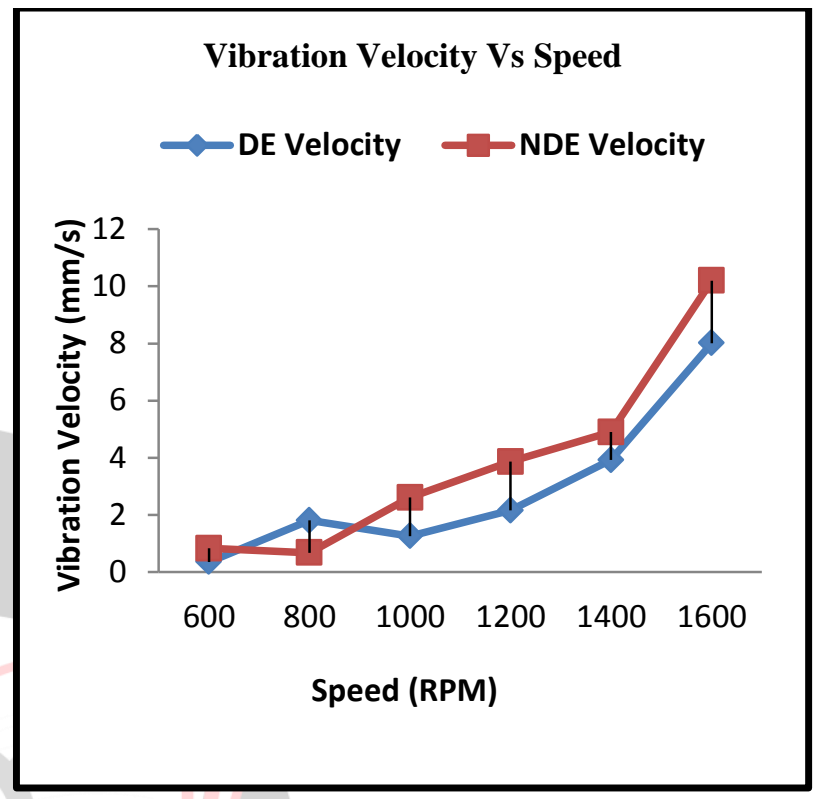

Figure 11 Velocity vs. Speed for Static Unbalance

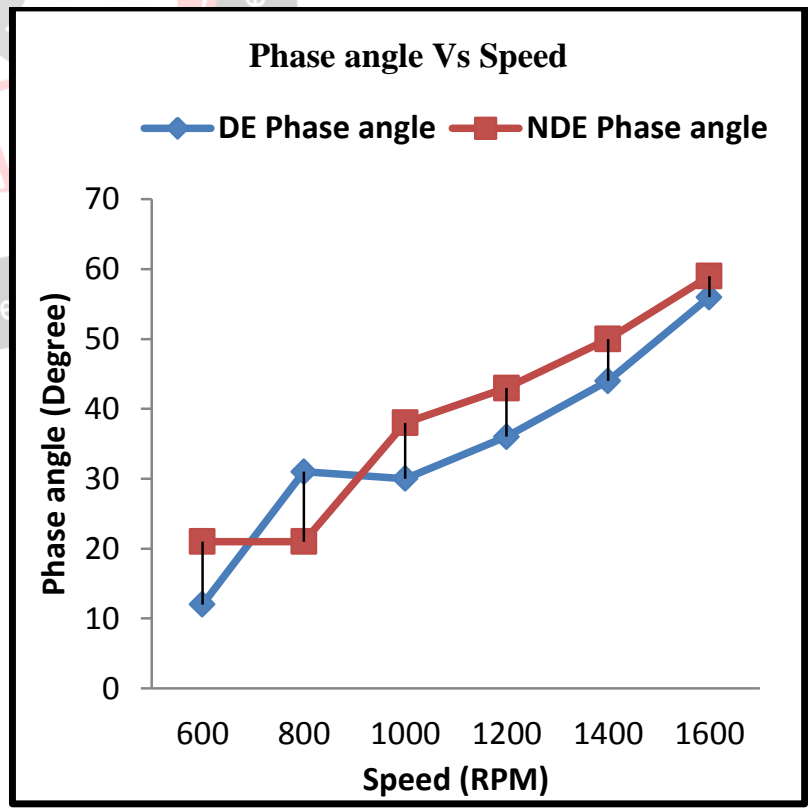

Figure 12 Phase angle vs. Speed for Static Unbalance

In case of static unbalance, the rotors supported between the bearings shows approximately equal vibration amplitude and phase angle readings measured at the bearings at each end of the shaft as shown in figure 11 and figure 12. Thus static unbalance can be detected by observing equal vibration amplitude and phase angle readings at both end bearings. 
Effect of Couple Unbalance on Vibration Parameters at Various Rotor Speeds

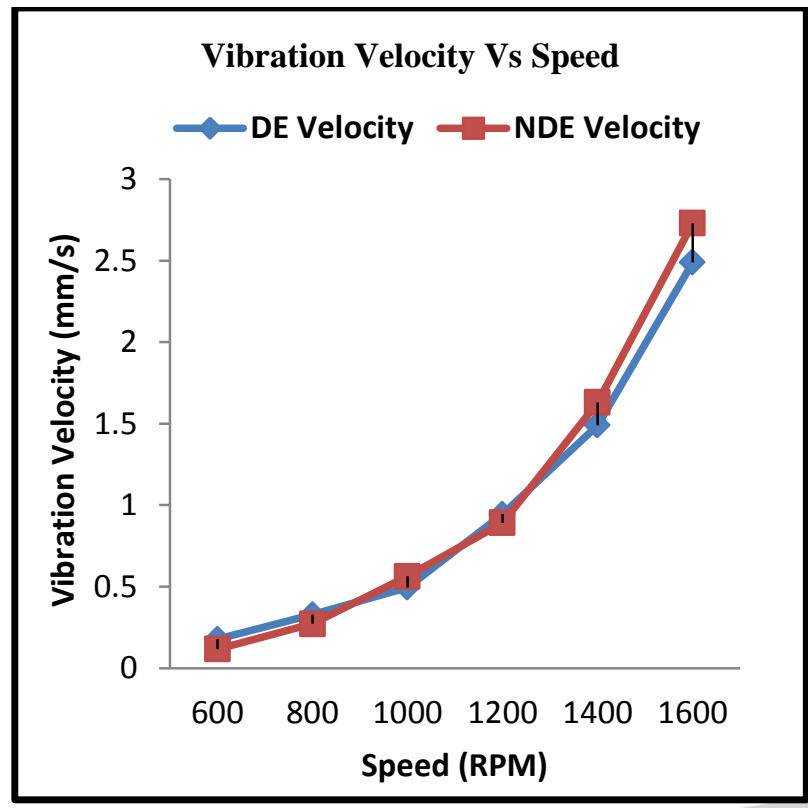

Figure 13 Velocity vs. Speed for Couple Unbalance

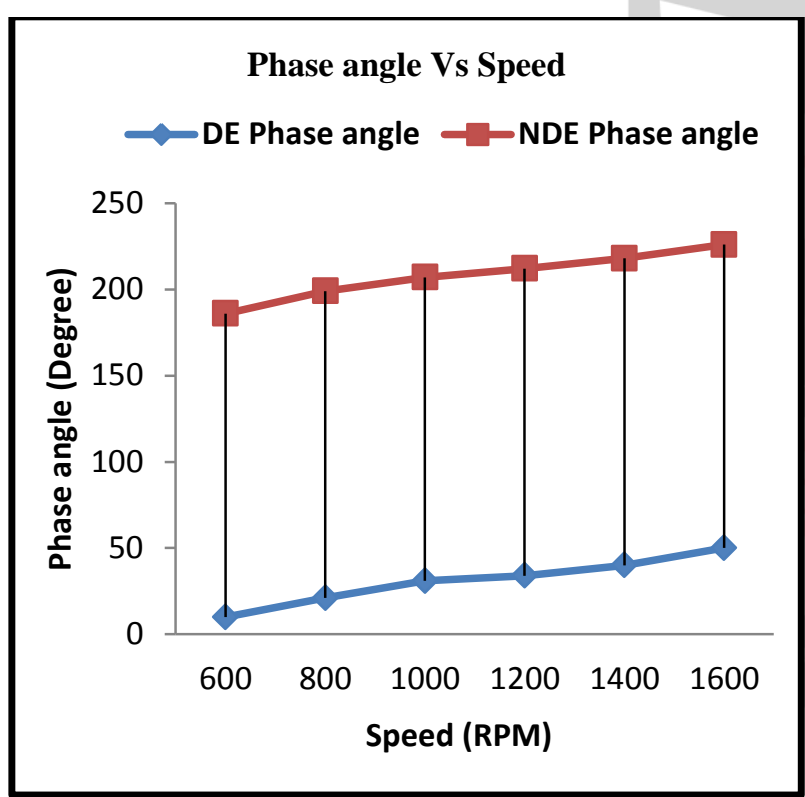

Figure 14 Phase angle vs. Speed for Couple Unbalance

In case of couple unbalance the rotors supported bearings shows equal amplitudes of vibration but the phase readings differ by $180^{\circ}$ as shown in figure 13 and figure 14 . Thus couple unbalance can be identified by comparing the bearings vibration amplitude and phase readings at each end of the rotor.
Effect of Quasi-static Unbalance on Vibration Parameters at Various Rotor Speeds

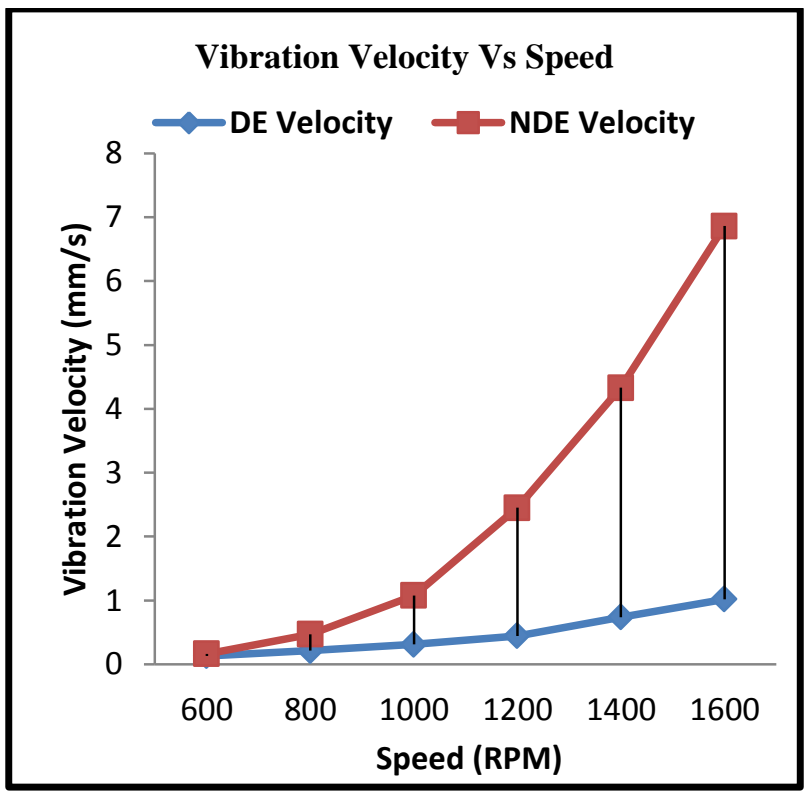

Figure 15 Velocity vs. Speed for Quasi-static Unbalance

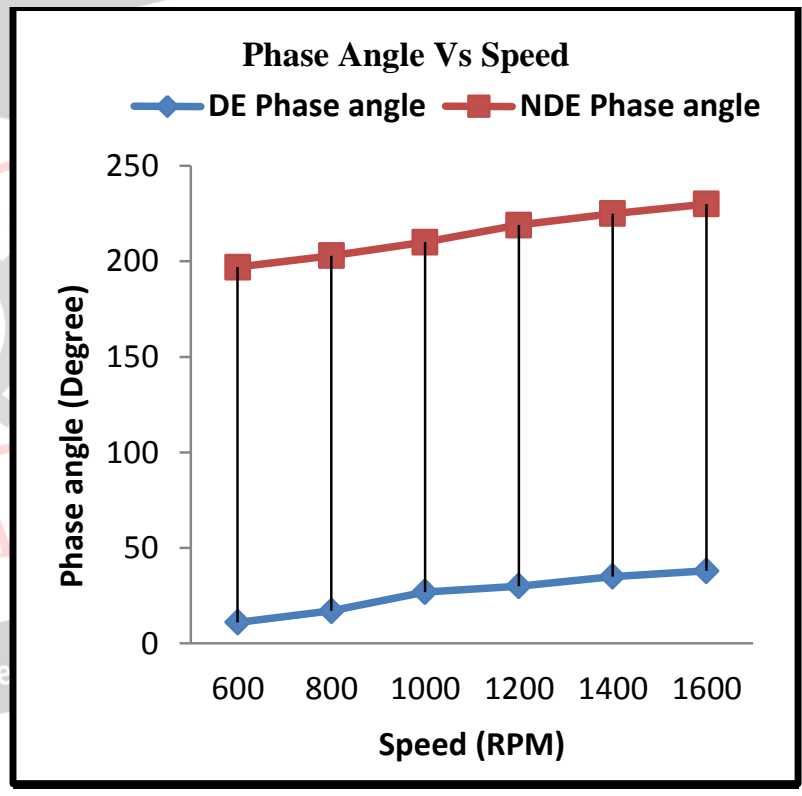

Figure 16 Phase angle vs. Speed for Quasi-static unbalance

In case of quasi-static unbalance, the rotors supported between bearings shows phase readings differ by approximately $180^{\circ}$ as shown in figure 16 . The amplitude of vibration is higher on non-drive end bearing as shown in figure 15 . This is because of trial mass attached on plane 3 is in line with trial mass on plane 4 and near to non-drive end. Thus if the bearing shows the phase readings differ by $180^{\circ}$ and higher vibration amplitude on one of the bearing, then quasi-static unbalance is present in the rotor. 
Effect of Dynamic Unbalance on Vibration Parameters at Various Rotor Speeds

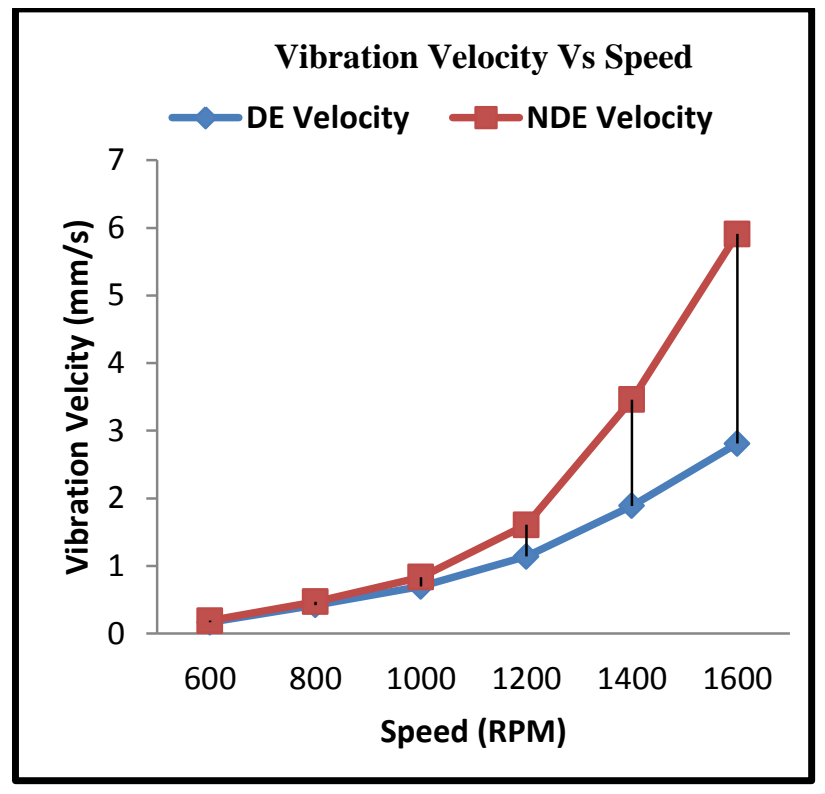

Figure 17 Velocity vs. Speed for Dynamic Unbalance

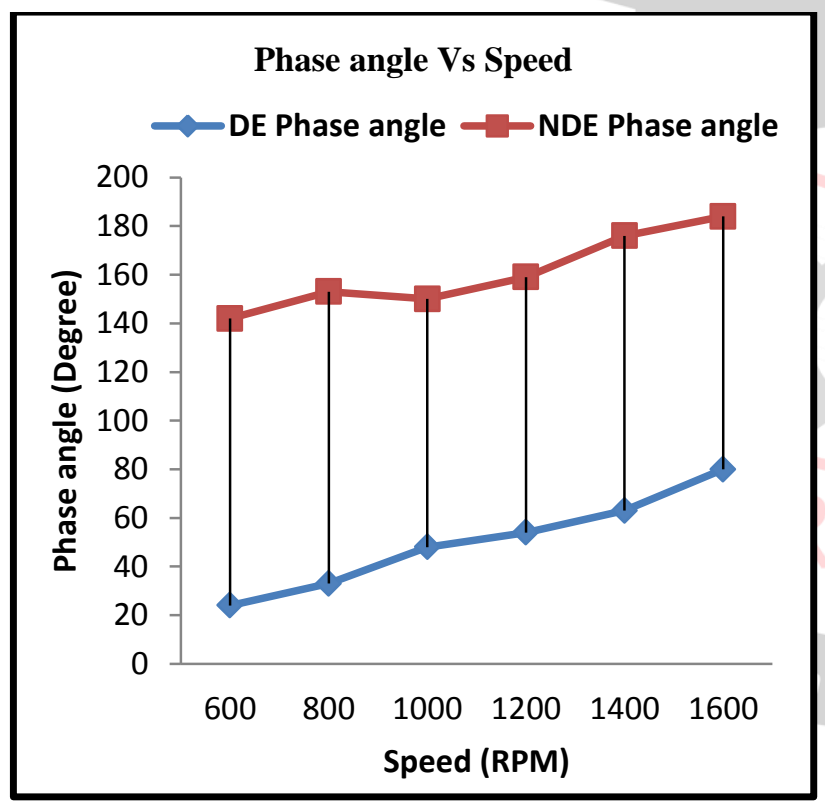

Figure 18 Phase angle vs. Speed for Dynamic Unbalance

Figure 17 and 18 shows that in case of dynamic unbalance phase readings which are neither the same nor directly opposite to one other.

\section{CONCLUSION}

It is observed that from this new method, it is possible to find the approximate location of unbalance heavy spot. This study showed that the proposed balancing method is very effective, practical and saving lots of time, cost and efforts because it requires only two test runs vibration data without trial weight. Further study can be carried out with the help of Jeffcott rotor model to find out approximate amount of unbalance mass. The importance of identifying type of rotor unbalance (static, couple, quasi-static, or dynamic) and the method to detect type of unbalance present in the rotor is presented. The graphs plotted from vibration readings for different types of unbalance gives following conclusions-

1. The static unbalance can be detected by observing equal vibration amplitude and phase readings at both bearings.

2. The couple unbalance can be identified by comparing the bearings vibration amplitude and phase readings at each end of the rotor.

3. If the bearing shows the phase readings differ by $180^{\circ}$ and higher vibration amplitude on one of the bearing, then quasi-static unbalance is present in the rotor.

4. The Dynamic unbalance shows phase readings which are neither the same nor directly opposite to one other

\section{REFERENCES}

[1] Chigbogu C. Ozoegwu, Christian C. Nwangwu, Chigozie F. Uzoh, Arinze V. Ogunoh, "Pure Analytical Approach to Rotational balancing", Journal of Safety engineering 2012, 1(4): 50-56

[2] Zhao Qing-Liang, Wang Hua-Qing and Yao JianFie, "A Novel Method of Dynamic Balance Weighting for Single Disk Rotor System", WSEAS Transactions on System E-ISSN: 22242678, Vol-11, Issue-1, January 2012.

[3] Xiaoping Yu. "General Influence Coefficient Algorithm in Balancing", International Journal of Rotating Machinery, v. 10, pp. 85-90, 2004.

[4] Troy D. Feese and Phillip Grazier "Case histories from difficult balance jobs", presented at the 33rd turbo-machinery symposium in September 2004.

[5] Eduardo Preciado Delgado and Roy H. Bannister, "Blancing of an Experimental Rotor Without Trial Runs", International journal of Rotating machinery, 8(2), 99-108, 2002

[6] S. Zhou and J. Shi, "Optimal One-Plane Active Balancing of Rigid Rotor During Acceleration", Journal of Sound and Vibration (2002) 249 (1), 196-205

[7] Shiyu Zhou and Jianjun Shi, “Active Balancing and Vibration Control of Rotating Machinery: A Survey", The shock and Vibration Digest, Vol. 33, No. 4, July 2001, 361-371

[8] W. C. Foiles, P. E. Allaire and E. j. Gunter, "Review: Rotor Balancing", Shock and Vibration 5 (1998) 325-336

[9] A.G. Parkinson, "Balancing of Rotating Machinery", Journal of Mechanical Engineering Science, v. C, p. 53-66, January 1991.

[10] V. Ramamurti and K.V.Anantaraman, "Two plane in situ balancing", Journal of Sound and Vibration, v. 134 (2), p. 343-352, 1989.

[11] Louis J. Everett "Two plane balancing of a rotor system without phase response measurement", Journal of Vibration, Acoustics, Stress and Reliability in Design, v. 109, pp. 162-167, 1987. 
[12] L. J. Everett, "Optimal Two-Plane Balancing of Rigid Rotors", Journal of Sound and Vibration (1997) 208 (4), 456-663

[13] Brendan P. Cunningham, "Dynamic balancing explained- a comparison of shop vs in field methods"

[14]Randall L. Fox "Dynamic balancing", IRD Mechanalysis Application Report number 111

[15] Prof. A. M. Patil, Prof. P. B. Kadam and Prof. R. S. Mithari, "Vibration Analysis of Bearing using FFT Analyser", International Journal of Advanced Technology in Engineering and Science, Volume No.02, Issue No. 04, April 2014.

\section{ACKNOWLEDGMENT}

I would like to express my deepest, humble and sincere gratitude to Prof. A. U. Paranjpe for his guidance, his continuous support, encouragement and help extended at every stage of this research work. His dynamism, vision, sincerity and motivation have deeply inspired me.

I express my gratitude and earnest thanks to Prof. Dr. S. P. Chavan Mechanical Engineering Department, Walchand College of Engineering, Sangli for providing me all facilities throughout the research work and for given me an opportunity to work on different case studies related to research in many sugar factories.

\section{ABBREVIATIONS}

\begin{tabular}{|l|l|}
\hline $\mathbf{B}$ & Measurable amplitude of the response \\
\hline $\boldsymbol{\beta}$ & Phase of the response \\
\hline $\mathbf{R}_{\mathbf{m}}$ & Damping factor \\
\hline $\mathbf{e}$ & Eccentricity \\
\hline $\mathbf{k}$ & Stiffness \\
\hline $\mathbf{\omega}$ & Angular speed \\
\hline $\mathbf{m}$ & Magnitude of unbalance \\
\hline $\mathbf{r}$ & $\begin{array}{l}\text { Radius of unbalance heavy spot from } \\
\text { rotating axis }\end{array}$ \\
\hline
\end{tabular}

